\title{
Trans-arterial Onyx Embolization of a Functional Thoracic Paraganglioma
}

\author{
Tatiana Chacón-Quesada, MD', Gustavo J. Rodriguez, MD²*, Alberto Maud, MD², \\ Luis Ramos-Duran, $\mathbf{M D}^{3}$, Alireza Torabi, MD4, Tamara Fitzgerald, MD, PhD $^{5}$, \\ Nassim Akle, MD $^{3}$, Salvador Cruz Flores, MD $^{2}$, Todd Trier, MD $^{6}$
}

Paragangliomas are rare tumors of the endocrine system. They are highly vascular and in some cases hormonally active, making their management challenging. Although there is strong evidence of the safety and effectiveness of preoperative embolization in the management of spinal tumors, only five cases have been reported in the setting of thoracic paragangliomas. We present the case of a 19-yearold man with a large, primary, functional, malignant paraganglioma of the thoracic spine causing a vertebral fracture and spinal cord compression. To our knowledge this is the first report of preoperative trans-arterial balloon augmented Onyx embolization of a thoracic paraganglioma.

Key Words : Paraganglioma; Embolization; Onyx

Catecholamine-secreting neuroendocrine tumors that arise from chromaffin cells of the adrenal medulla are known as pheochromocytomas, and are named paragangliomas when arising from the neuroendocrine cells of the extra-adrenal autonomic paraganglia. Paragangliomas are less often hormonally active than pheochromocytomas but are more likely to be malignant [1]. Most paragangliomas are intra-abdominal and adjacent to the adrenal glands. Intrathoracic paragangliomas are more often located in the anterior mediastinum, and when associated with the spine they tend to be located in the cauda equine [2]. Very few cases of presurgical embolization of paragangliomas located in the thoracic spine have been reported [3-7]. To our knowledge this is the first report of Onyx embolization of a malignant, functioning thoracic paraganglioma.

\footnotetext{
${ }^{1}$ Center of Excellence in Neurosciences, Texas Tech University Health Sciences Center, Paul L. Foster School of Medicine, EL Paso, TX, USA 2Department of Neurology, Texas Tech University Health Sciences Center, Paul L, Foster School of Medicine, EL Paso, TX, USA ${ }^{3}$ Department of Radiology, Texas Tech University Health Sciences Center, Paul L, Foster School of Medicine, EL Paso, TX, USA ${ }^{4}$ Department of Pathology, Texas Tech University Health Sciences Center, Paul L, Foster School of Medicine, EL Paso, TX, USA ${ }^{5}$ Department of Pediatric Surgery, Texas Tech University Health Sciences Center, Paul L, Foster School of Medicine, EL Paso, TX, USA ${ }^{6}$ Department of Neurosurgery, University Medical Center, EL Paso, TX, USA Received February 7, 2015; accepted after revision February 12, 2015.

Correspondence to: Gustavo J. Rodriguez, MD, Department of Neurology, Texas Tech University Health Sciences Center, 4800 Alberta Ave. El Paso, Texas. 79905, USA.

Tel. +1 915.215.5900 Fax. +1915.545 .6705$

E-mail: gustavo.j.rodriguez@ttuhsc.edu

This is an Open Access article distributed under the terms of the Creative Commons Attribution Non-Commercial License (http://creativecommons.org/licenses/by-nc/3.0) which permits unrestricted non-commercial use, distribution, and reproduction in any medium, provided the original work is properly cited.
} 


\section{CASE REPORT}

A 19-year-old man with 6-year history of chest pain and 6 months of progressive paraplegia with associated hypertension was admitted for further work up of a known mass in the thoracic spine. MRI findings evidenced a thoracic tumor extending from T4 to T9 with an associated T6 vertebral fracture and a L3 metastatic lesion (Fig. 1A and 1B). Iodine-123 metaiodobenzylguanidine scintigraphy (I-123 MIBG) showed intense uptake within the same areas (Fig. 1C). A spinal digital subtraction angiography (DSA) showed a prominent tumor blush, with arterial feeders arising from the right $\mathrm{T} 5$ through $\mathrm{T} 10$ intercostal arteries. The most prominent arterial feeders were $\mathrm{T} 7$ through $\mathrm{T} 9$
(Fig. 2A).

An ultrasound guided biopsy confirmed it to be a paraganglioma (Fig. 3A and 3B). There was no history of any associated familial syndromes and genetic testing did not display any known abnormality.

A functional, malignant thoracic paraganglioma was diagnosed and sequential alpha and beta blocker was started in preparation for a staged combined treatment. The patient underwent a successful presurgical tumor embolization of arterial feeders coming from the right T7, T8 and T9 intercostal arteries in three consecutive days, using liquid embolic material (Onyx ,Covidien Inc., Irvine, CA) through a $4 \times 10 \mathrm{~mm}$ Scepter-C balloon catheter (Microvention Inc., Tustin, CA). The presurgical augmented embolization archived more than $90 \%$ reduction of the tumor blush (Fig. 2B).

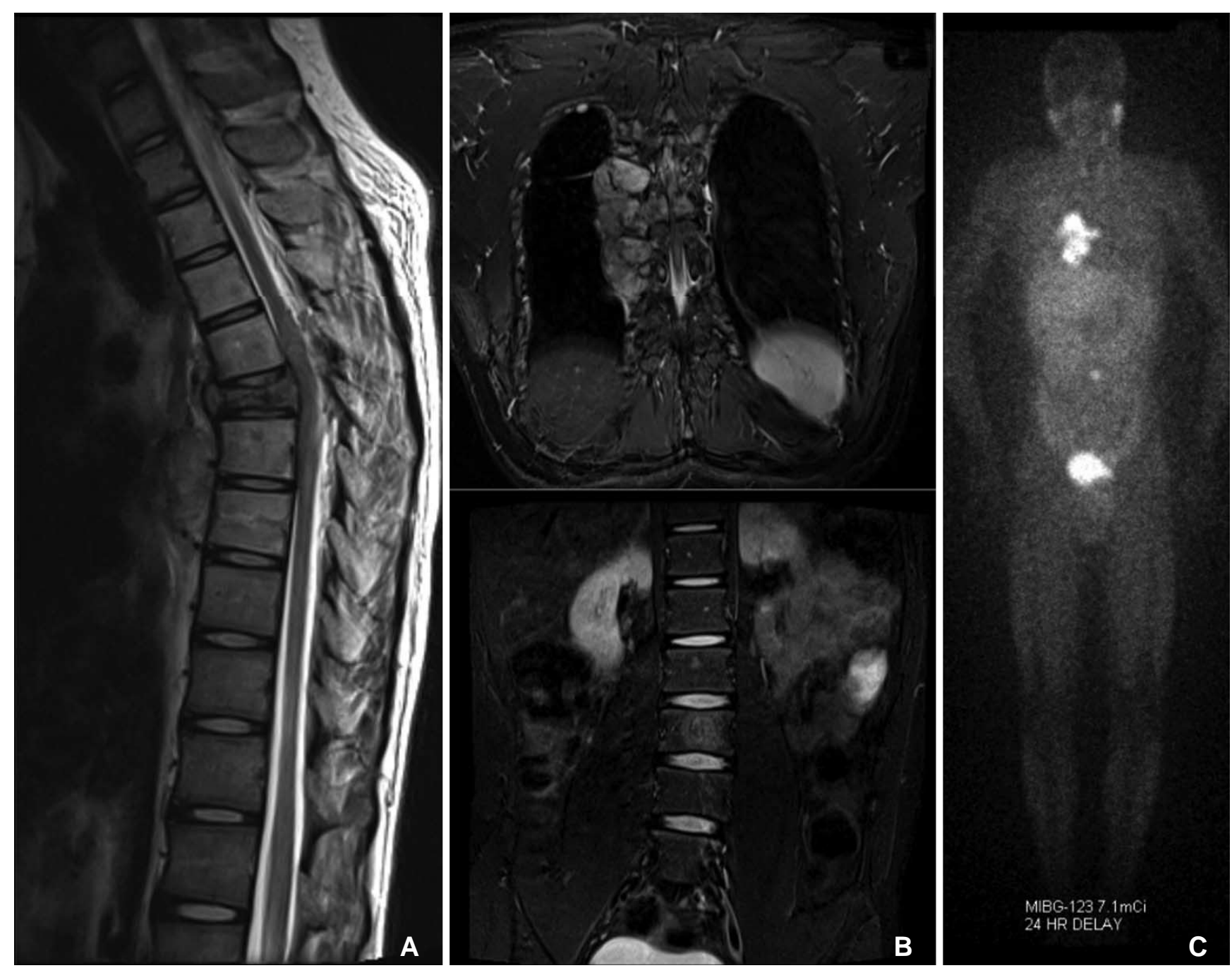

Fig. 1. Diagnostic imaging. A. Sagittal T2-weighted image demonstrating a pathologic T6 compression fracture and cord edema. B. Coronal STIR (upper) showing a paraspinal and intraspinal extradural heterogeneous enhancing mass extending from T4-T9 causing widening of the neural foramina and severe canal stenosis. There was a separate metastatic hyperintense lesion in L3 vertebral body (lower B). C. I-123 MIBG whole body AP view demonstrated intense uptake within the large right paravertebral mass and separate L3 lytic lesion. 


\section{Tatiana Chacón-Quesada, et al.}

The surgical treatment consisted of two stages. In the first surgery the patient had a partial $\mathrm{T} 5$, complete $\mathrm{T} 6$, partial T7 laminectomy, and pedicle screw fixation of T4, T5, T7, and T8 with posterolateral fusion. The surgery lasted 7.5 hours with an estimated blood loss of $700 \mathrm{ml}$. A second surgery five days later consisted of a right posterolateral thoracotomy and total gross resection of the thoracic paraganglioma (Fig. 3C). It lasted 7 hours with an estimated blood loss of $4500 \mathrm{ml}$ requiring 4 units of packed blood cells, 10 units of platelets, 4 units of fresh frozen plasma and $500 \mathrm{ml}$ of albumin. Of note, prior to the admission the patient had an attempted tumor resection through a right thoraco- tomy in another hospital where the procedure was abandoned due to a significant blood loss. Microscopic examination of the resected specimen showed coagulative necrosis of the tumor with the embolic material completely occluding an artery and some viable tumor cells after the embolization (Fig. 3D and 3E).

Hemodynamic instability was observed during every procedure despite appropriate alpha and beta blockade. This coincided with the manipulation of the tumor, either vascular or mechanic. The response was less intense after every intervention and was managed pharmacologically without complications (Table 1).

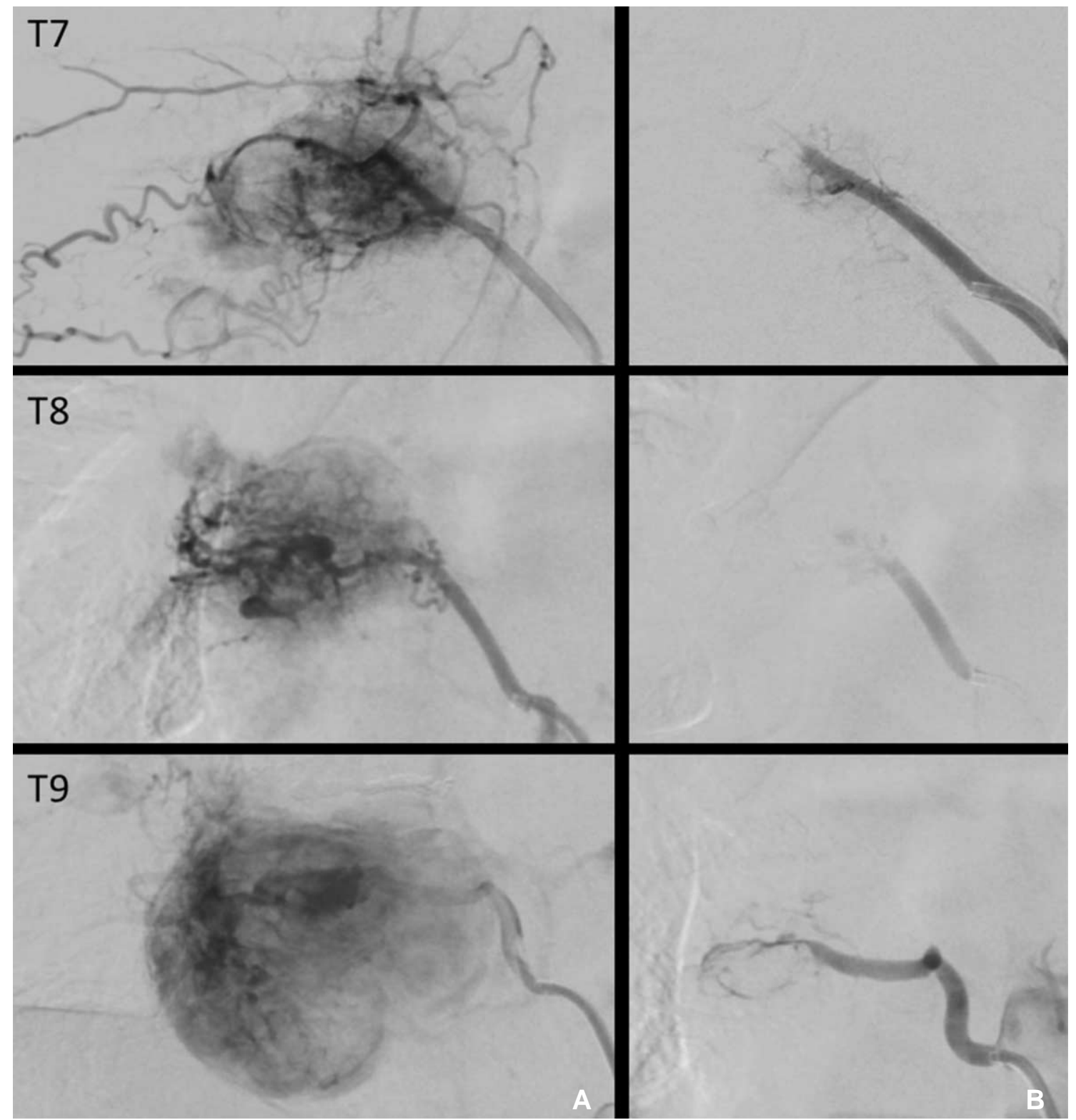

Fig. 2. Digital Subtraction Angiography. A. Diagnostic angiogram in the anterior-posterior view shows a highly vascular tumor. Note the prominent tumor blush within the main feeders (T7-T9). B. Control angiogram after each ONYX embolization reveals complete devascularization with no residual tumor blush. 


\section{Paraganglioma Onyx Embolization}

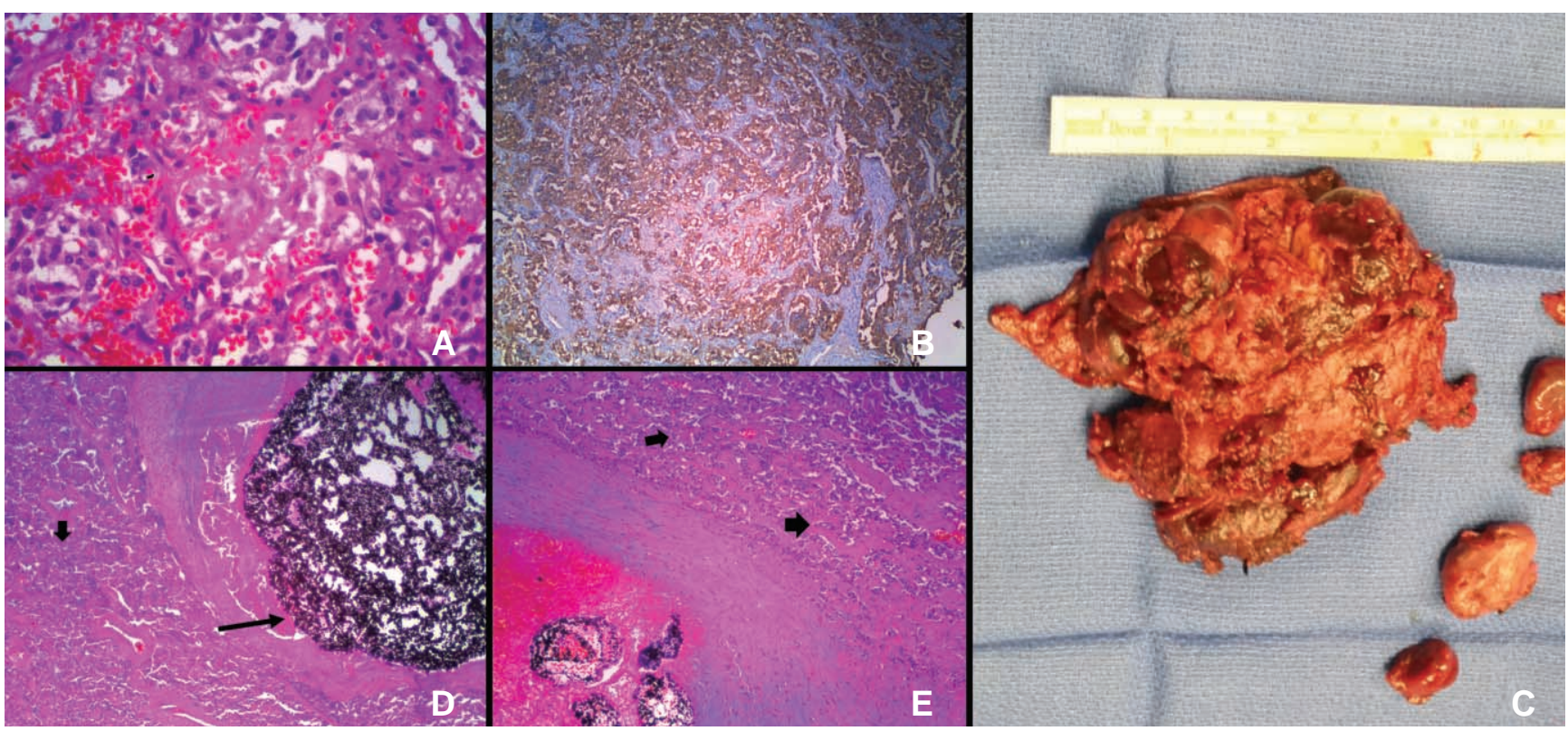

Fig. 3. Pathology. A. Nests of tumor cells (Zellballen) composed of uniform cells with round nuclei, eosinophil cytoplasm in a highly vascular stroma (Haematoxylin and Eosin, 40X). B. Inmmunohistochemical staining of the tumor showing positivity for Chromogranin (10x). C. A tumor measuring $10 \times 7 \times 3 \mathrm{~cm}$ resected in the second surgery. Microscopic examination of the resected mass evidence $\mathbf{D})$ $50 \%$ coagulative necrosis of the tumor (black arrow) with the embolic material completely occluding an artery, and E) some viable tumor cells after the embolization (black arrows) (Haematoxylin and Eosin, 10X).

Table. Hemodynamic Changes Observed During the Staged Treatment

\begin{tabular}{|c|c|c|c|}
\hline Procedure & $\begin{array}{l}\text { Highest Blood } \\
\text { Pressure } \\
\text { (mmHg) }\end{array}$ & $\begin{array}{l}\text { Heart } \\
\text { Rate } \\
\text { (bpm) }\end{array}$ & $\begin{array}{c}\text { Medications used } \\
\text { to control } \\
\text { blood pressure }\end{array}$ \\
\hline T8 embolization & $224 / 145$ & 105 & $\begin{array}{c}\text { Labetalol } \\
\text { Esmolol }\end{array}$ \\
\hline T9 embolization & $220 / 100$ & 61 & $\begin{array}{c}\text { Hydralazine } \\
\text { Nicardipine drip } \\
\text { Nitroprusside drip }\end{array}$ \\
\hline T7 embolization & $180 / 84$ & 60 & $\begin{array}{l}\text { Labetalol drip } \\
\text { Nicardipine drip }\end{array}$ \\
\hline $\begin{array}{l}\text { Surgical } \\
\text { decompression with } \\
\text { spinal stabilization }\end{array}$ & $200 / 110$ & 92 & $\begin{array}{c}\text { Hydralazine } \\
\text { Esmolol } \\
\text { Labetalol } \\
\text { Nitroprusside drip }\end{array}$ \\
\hline Tumor resection & $190 / 100$ & 100 & $\begin{array}{l}\text { Labetalol } \\
\text { Esmolol } \\
\text { Nitroprusside } \\
\text { Nicardipine }\end{array}$ \\
\hline
\end{tabular}

\section{DISCUSSION}

This is a case of a large thoracic, functional malignant paraganglioma treated with trans-arterial Onyx embolization of its three major vascular feeders and two subsequent surgeries. Surgical excision is the gold standard treatment for paragangliomas. There is no consensus in the definition of malignant paraganglioma and the only consistent criterion among the proposed indicators is the presence of metastatic disease. More importantly, no histological criteria have shown to be a reliable marker of aggression.

The hypervascular nature of these tumors associated with other characteristics, like location and catecholamine secretion make their resection challenging. For this reason presurgical embolization can be a valuable and safe tool in the management of these tumors as it has been shown to reduce the risk of catecholamines release during surgical manipulation of the tumor, decrease the intraoperative blood loss, and decrease the number of transfusions, therefore reducing the operative time, complications and local recurrence $[4,5,8]$.

In our case, each presurgical embolization resulted in a reduced catecholamine secretion as evidenced by the subsequent reduction in the magnitude of the hypertensive response. Although there was a significant blood loss during the surgical excision of the tumor in our case, we believe that it would have been more prominent without the embolization. As discussed by other authors, the estimated blood loss and operative time are influenced by other factors other than the embolization, like invasiveness of the procedure and 
surgical approach [9].

To date, only five cases of presurgical embolization of thoracic paragangliomas have been reported [3-7]. Only one of them was functional, and differs from our case in that it was a metastatic lesion involving one vertebral level [5]. The embolic materials reported included Gelfoam and the most commonly used Polyvinyl alcohol, all with positive results. Ghobrial et al showed the feasibility of trans-arterial embolization with Onyx in the management of spinal tumors although most of their cases represented by metastatic renal cell carcinomas. When compared with other agents, Onyx demonstrated higher rates of angiographic obliteration and intraoperative bleeding reduction, although the difference did not reach statistical significance [8]. Advantages of Onyx are related to its properties that permit more control and longer injections and deeper penetration through the tumor vascularity. It also gives excellent surgical handling properties that help with the tumor resection $[8,10]$.

In summary, the treatment goal of functional thoracic paragangliomas is surgical resection. Surgery however is very challenging due to hemodynamic instability and prominent hemorrhagic tendency. Pre-surgical embolization significantly helps to decrease these adverse events. The combination of Onyx with the Scepter C balloon seems to be a good option when aggressive embolization of functional thoracic paraganglioma is intended.

\section{Acknowledgements}

Research reported in this publication was supported by the Fogarty International Center of the National Institutes of Health under Award number D43TW008333. U.S./
Costa Rica Neuropsychiatric Genetics Research training program.

\section{References}

1. Laird AM, Gauger PG, Doherty GM, Miller BS. Paraganglioma: not just an extra-adrenal pheochromocytoma. Langenbecks Arch Surg 2012;397:247-253

2. Ilias I, Pacak K. A clinical overview of pheochromocytomas/ paragangliomas and carcinoid tumors. Nucl Med Biol 2008;35 Suppl 1:S27-S34

3. Brodkey JA, Brodkey JS, Watridge CB. Metastatic paraganglioma causing spinal cord compression. Spine 1995;20:367-372

4. Cybulski GR, Nijensohn E, Brody BA, Meyer PR, Jr., Cohen B. Spinal cord compression from a thoracic paraganglioma: case report. Neurosurgery 1991;28:306-309

5. Kwan RB, Erasmus AM, Hunn AW, Dubey A, Waites P, Jessup PJ, et al. Pre-operative embolisation of metastatic paraganglioma of the thoracic spine. J Clin Neurosci 2010;17:394-396

6. Noorda RJ, Wuisman PI, Kummer AJ, Winters HA, Rauwerda JA, Egeler-Peerdeman SM. Nonfunctioning malignant paraganglioma of the posterior mediastinum with spinal cord compression. A case report. Spine 1996;21:1703-1709

7. Shin JY, Lee SM, Hwang MY, Sohn CH, Suh SJ. MR findings of the spinal paraganglioma : report of three cases. J Korean Med Sci 2001;16:522-526

8. Ghobrial GM, Chalouhi N, Harrop J, Dalyai RT, Tjoumakaris S, Gonzalez LF, et al. Preoperative spinal tumor embolization: an institutional experience with Onyx. Clin Neurol Neurosurg 2013; 115:2457-2463

9. Kobayashi K, Ozkan E, Tam A, Ensor J, Wallace MJ, Gupta S. Preoperative embolization of spinal tumors: variables affecting intraoperative blood loss after embolization. Acta Radiol 2012;53: 935-942

10. Gore P, Theodore N, Brasiliense L, Kim LJ, Garrett M, Nakaji P, et al. The utility of onyx for preoperative embolization of cranial and spinal tumors. Neurosurgery 2008;62:1204-1211 